\title{
A pilot study of dual diagnosis training in prisons
}

\author{
Elizabeth Hughes \\ Principal Research Fellow, Centre for Clinical and Academic Workforce Innovation, University of Lincoln
}

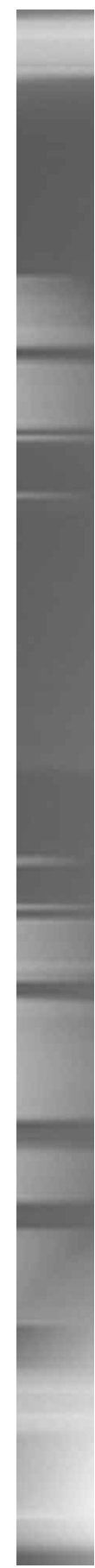

\section{Abstract}

People with dual diagnosis have complex needs and vulnerabilities that may lead to incarceration in prisons. Mental health and substance use services in prisons should have the capabilities to address their needs while incarcerated and facilitate the transfer of care to community services on release. In order to develop these capabilities, a training programme is required.

A pilot training programme for dual diagnosis was developed and piloted in five London prisons. The training was based on a training needs assessment of prison staff and consultation with service users. It was delivered in two forms: a fiveday classroom based course, and a 'blended learning' method that comprised a manual and three sessions of supervision. The course was evaluated by a brief questionnaire that included items on attitudes, self-efficacy and knowledge about working with dual diagnosis.

The evaluation of the training revealed that all workers, no matter what method of training they received increased their perception of their skills (self-efficacy) and increased their attitudes. Knowledge remained the same (although the scores pre-training were high). There was no difference between the two types of training when mean scores were compared at post-training. There was also no difference between the mental health and substance workers regarding their mean scores at follow-up, apart from knowledge.

The conclusion is that the training pilot was evaluated positively and did indicate that it has some effect on attitudes and self-efficacy. More rigorous evaluation of the impact of the training is required, using a robust methodology and assessing the impact on clinical skills and service user outcomes.

\section{Keywords}

prison; mental health; dual diagnosis; training

\section{Background}

Addressing the needs of people with dual diagnosis (mental health and substance use problems) has been identified as a major challenge for mental health services in England (DoH, 2005). The outcomes for people with dual diagnosis are likely to be poor and they are likely to have a substantial amount of unmet needs. Areas of vulnerability include increased risk of suicide, violence, victimisation, health problems (such as blood borne infections), poor adherence to treatment, and homelessness. People with dual diagnosis often fail to receive appropriate care due to a combination of difficulties with engagement, lack of clarity around service responsibilities and lack of capabilities of the mental health and substance use workforce. The lack of engagement and the complexity of their problems can result in criminal behaviours and ultimately imprisonment.

While there are no actual figures of the prevalence of co-morbid substance use and mental health in the prison system, it is estimated that the level of dual diagnosis is likely to be significant (Brooker et al, 2003). Surveys (ONS, 1997 ; 1998) estimate that $70 \%$ of prisoners have at least one diagnosable mental illness or substance use problem. Often prisoners have multiple diagnoses. These prisoners are at high risk for suicide. Shaw, Appleby and Baker (2003) reported that $32 \%$ of people who committed suicide while in prison had two co-morbid diagnoses. Reoffending rates are also high as co-morbid mental health and substance use compound the difficulties (lack of housing, support, access to care etc.) associated with release from prison that most prisoners experience (Social Exclusion Unit, 2002; Home Office, 2004). For example, around half of people with mental illness who are released from prison lack stable housing (Revolving Door, 2002).

Despite the modernisation of both mental health (DoH/HM Prison Service, 2001) and substance use services (HM Prison Service, 1998; 2000) within prisons, there is a lack of clarity as to who should be providing care for prisoners with both mental health and substance use problems, and a lack of skills and knowledge among workers to provide that care. 
The Sainsbury Centre for Mental Health (SCMH) (2006) found that in their review of prison mental health in-reach teams, there was a 'big gap' in service provision for dual diagnosis, and mental health and substance use teams tend to refer people on to other services, rather than seek to work jointly. SCMH (2006) suggests that given the high level of co-morbidity, addressing the needs of these prisoners should be core business of the mental health teams.

The Practice Implementation Guide for Dual Diagnosis (DoH, 2002) advocates that care for people with serious mental health problems should be delivered by mental health services with some help and support from substance use services ('mainstreaming'). People with primary substance use problems who have minor mental disorders (such as anxiety or depression) should be managed primarily by substance use services with some support from mental health if required. The implication is that workers in both settings will need to be able to work holistically and comprehensively with everyone with dual diagnosis. Therefore, they should possess the appropriate capabilities. This policy guidance equally applies to prisons. However, the prison substance use workers are not likely to have a mental health background, and therefore can't take the role that the community drug and alcohol services provide outside the prisons. In addition, it is likely that many mental health workers in prison lack skills in substance use interventions.

Therefore, in order to address the issue of improving care for people with dual diagnosis within prison, the first step should be to improve the way mental health and substance use services interface, and to improve the capabilities of workers in these services to detect, assess, and intervene using an evidence and values-based framework of intervention.

\section{Prison dual diagnosis training pilot project}

The overall aim of the project was to develop and pilot a set of relevant and effective training materials that will assist mental health and substance use staff in their care of people with dual diagnosis within the prison service. The target groups for the training were those who spent the most time working therapeutically with prisoners with dual diagnosis, namely health care staff, prison substance use counsellors (Counselling, Assessment,
Referral, Advice and Throughcare Services - CARATS), detoxification staff, primary care, and mental health inreach staff. Prison officers were invited to participate if they had a specific role in health care.

\section{Method}

The first stage of the project was to engage the prison sites for the delivery of the training. All health care managers, in-reach team managers and substance use service managers at all London prisons were contacted (via email and telephone). The project manager met with key personnel at these prisons to explain the aims of the project and to discuss whether it could be implemented at their institution, and by which method. Most of the prisons agreed to participate: HMP Wormwood Scrubs, HMP Wandsworth, HMP Belmarsh, HMP/YOI Feltham and HMP Highdown. An information sheet was provided for trainees, which outlined the project aims, methods of delivery, and the dates for the training at their own establishment. The link worker at each site co-ordinated the recruitment of trainees, and the booking of suitable training venues.

The second stage of the project was the training needs assessment. This comprised a semi-structured questionnaire asking about a range of issues relating to the care of dual diagnosis prisoners and the perceived training needs. The aim of this instrument was to gain an understanding about:

- how staff currently worked with people with dual diagnosis

- what they regarded as the needs of people with dual diagnosis in prison

- their views on the ideal content of a training package.

Of 80 questionnaires distributed by the link workers at each prison, 23 were completed and returned, and this represents a response rate of $29 \%$. This is not unusual for postal-return method of prison staff (Brooker et al, 2006). A more effective method would have been face-to-face interviews but given the time-frame and the difficulties of accessing staff within prisons, this seemed to be the most pragmatic method. Although the respondents represented a good cross section of the services that would be targeted for the training, the low numbers make it difficult to generalise the results across the service. The breakdown of respondents was as follows: 
- CARATS workers - 5

- RAPt (rehabilitation of Addicted Prisoners Trust) - 1

- mental health (in-reach and inpatient services) - 10

- detox -7

- health psychology - 1 .

Despite the low numbers, their responses gave an initial understanding of the perceived training needs.

They reported that the most common mental health problems encountered were schizophrenia, then depression and drug-induced psychosis (no mention of personality disorders). The most common substance use problems encountered were heroin and alcohol followed by crack cocaine. They usually offered assessment and referral to prisoners with dual diagnosis and lacked a framework for interventions. They were able to identify appropriate values and attitudes and general interpersonal skills that should be used, but didn't mention more specific skills such as motivational interviewing or cognitive behavioural interventions for psychosis. They thought that multi-agency working could be good, but often poor communication and a lack of clarity about roles and responsibilities acted as barriers to this. They mentioned that resource issues (lack of staff and time) acted as barriers to providing anything more than brief assessment. In addition, security requirements of the prison restricted the access of health professionals to prisoners on the wings. The respondents reported very little previous training relevant to dual diagnosis. Generally, if people had accessed training it was in the form of brief one-day workshops or lectures. None of the addictions workers who completed the questionnaire had any previous mental health training, and mental health workers had little previous substance use experience.

The conclusions drawn from the training needs assessment were:

1. Mental health and substance use workers work together infrequently and there is a lack of communication and sharing of information between services in prison (and outside).

2. The respondents understood little about each other's role and how a person with dual diagnosis should be navigated through these services both within the prison and outside.

3. They identified general basic skills, knowledge and attitudes for work with people with a dual diagnosis, but lacked a theoretical framework on which to base their interventions.

4. They lacked an overall strategy or framework that could guide care.

5. There was a significant lack of clarity about their own training needs apart from an acknowledgement that they wanted to know more about dual diagnosis issues.

6. The respondents lacked basic training in mental health and substance use awareness, as well as the more specific dual diagnosis issues.

\section{Service user consultation}

A group of four service user consultants with some experience of a mental health and substance use problem (some also had personal experience of the criminal justice system) attended a consultation meeting. They were asked a series of open-ended questions. A transcript was produced and the participants were given a copy to approve before it could be included in the report of the project.

From the discussion, it emerged that the service users felt that workers from mental health and substance use services lacked competence and confidence in dealing with the complexity of dual diagnosis. Thus, they had found themselves excluded from help from a particular service until they had got the other problem sorted out. One participant described how he had been told that he could not continue with his psychological therapy for his mental health problem until he had stopped drinking. He felt that in order to stop drinking he needed help with his mental health problems. The service users felt that things could be improved if services were more willing to work with someone 'where they were at' in terms of motivation and lifestyle choices rather than forcing treatment options on to them. For example, rather than just offering detoxification, services could offer counselling to help motivate people before they make the decision to reduce or stop their substance use. They also felt that more counselling ('talking therapies') should be available. When asked about the knowledge, skills and values for helping people they talked mostly about the importance of the right attitudes (empathy, non-judgemental, acceptance). This would assist in the engagement process. They also talked about the importance of identifying and helping with social issues. Examples of important social issues were helping people find safe housing, and helping with the move away from an unhealthy peer group. In 
contrast the staff training needs responses did not mention social issues.

The service users thought that a training course should explore attitudes and should include drugs and alcohol awareness. Training should attempt to break down the 'them and us' barrier and help staff to see that 'we are all service users' of some kind or another. They wanted training to increase staff empathy. They also thought that training should help the workers to help the service users manage relapses better, not seeing lapses as treatment failure or lack of motivation, but utilising them as a learning experience. They also thought that role-play was an important way for staff to learn, and that service users should be involved in the delivery. They thought that staff should be evaluated by using case-studies and that they should be directly observed in practice.

In terms of ongoing support and learning, the service users thought that the trainees should be able to access supervision, and work alongside experienced workers. Workers should have a learning plan that maps out their development. They felt emphatically that service users should be involved in all aspects of training including delivery and evaluation. They felt that prisoners should be consulted about what they want.

In conclusion, the service users thought that a training package should address attitudes, increase empathy, and help workers to offer integrated care rather than referral elsewhere. They felt that training should be experiential and that there should be ongoing learning and supervision afterwards. They also emphasised the importance of service user involvement in all aspects of development and delivery of training.

\section{The training materials}

The training materials were developed from a five-day course that had been developed over the past five years at the Institute of Psychiatry, King's College London. This course had been used in two research trials of training for community mental health workers, and in a London wide dissemination project across most of the mental health NHS trusts (Brewin, 2004). The content was modified to be relevant to the prison settings. The training resource combined evidence and government policy relating to the care of people with dual diagnosis as well as relevant prison research and strategy documents including the Dual Diagnosis Good Practice Guide (2002), Integrated Treatment Approach, Motivational Interviewing, Cognitive Behavioural Techniques, and Relapse Prevention. In addition, the 10 Essential Shared Capabilities (2004) were also used as a basis for the values and ethos of the course. Feedback from the training needs assessment information and service user consultation also informed the content and delivery of the materials.

The training pack was designed to be delivered in a flexible way either as a traditional classroom based course, or as self-directed work-based learning (blended learning). It is divided into 16 modules, each module representing one to two hours of classroom teaching or self-directed learning sessions. The course could be delivered over five days or in smaller units over a longer period. Each module consists of a title page with an aim and approximately four objectives, and is mapped to specific capabilities from the Dual Diagnosis Capability Framework (Hughes, 2006). There is also space for participants to add their own personal objectives. There are sections of background reading about the specific subject, a small group discussion exercise, and a role play/skills practical (depending on the subject). The module ends with recommended further reading.

The manual is intended to be clinically relevant, simple to use and easy to read. It is not intended to be an exhaustive resource for dual diagnosis as there are already products in the public domain that serve this purpose (eg. the Rethink Dual Diagnosis Toolkit, undated internet resource). Neither is it intended to be a heavily referenced academic piece of work. Further reading and useful websites have been referenced at the end of each module for people to seek out if they so wish. 


\section{Training content}

\begin{tabular}{|c|c|}
\hline Module 1 & Introduction \\
\hline Module 2 & Drug and alcohol awareness \\
\hline Module 3 & Mental health awareness \\
\hline Module 4 & $\begin{array}{l}\text { Interaction of mental health and } \\
\text { substance use }\end{array}$ \\
\hline Module 5 & Assessment process \\
\hline Module 6 & Comprehensive assessment \\
\hline Module 7 & Physical health and assessment \\
\hline Module 8 & Risk \\
\hline Module 9 & Treatment models \\
\hline Module 10 & Stage 1 engagement phase \\
\hline Module 11 & $\begin{array}{l}\text { Stage } 2 \text { persuasion: building } \\
\text { motivation to change }\end{array}$ \\
\hline Module 12 & Resistance \\
\hline Module 13 & Stage 3 active treatment \\
\hline Module 14 & Stage 4 relapse prevention \\
\hline Module 15 & $\begin{array}{l}\text { Multi-agency working and service } \\
\text { delivery }\end{array}$ \\
\hline Module 16 & Practice development \\
\hline
\end{tabular}

\section{Implementation and evaluation}

Training was piloted at the five London prisons. Two prisons received a five-day (one day per week) classroom course $(n=23)$ and three received 'blended learning' $(n=40)$, which consisted of three supervision sessions that occurred fortnightly, plus the manual to work through.

The training was evaluated using a short questionnaire that included items about dual diagnosis attitudes, confidence in skills, and knowledge. Each item was rated on a five-point Likert scale, 1 representing disagree strongly and 5 agree strongly. The questions were adapted from questionnaires used in previous evaluations of dual diagnosis training (Hughes et al, in submission).

A total of 63 questionnaires were completed pretraining. The questionnaire was redistributed on the last day of training. If people were absent on the day, questionnaires were left with colleagues for the missing people to complete and post back.

A total of 44 follow-up questionnaires were received (70\%). This gives an attrition rate of 30\%. However, 13\% of the attrition can be accounted for from one prison site (blended learning). The data from the questionnaires was entered onto a database and analysed using SPSS 14 . The maximum possible score for attitude and confidence was 40, and maximum score for knowledge was 7 .

\section{Analysis of data}

As this was a scoping project, the data collected was limited to a brief questionnaire. Therefore the findings serve as indications only as to the effectiveness of the training methods. More rigorous research methods would need to be adopted to provide more definitive results.

All participants (no matter what method of delivery they were exposed to) were compared on the means of the subscales at baseline and follow-up using a paired sample t-test. Overall, there was a significant improvement at follow-up on attitudes and confidence in their skills towards people with dual diagnosis (see Table 1, overleaf). Knowledge scores remained unchanged, however, the scores were reasonably high at baseline with an average of five out of seven correct. The knowledge questionnaire would need to be expanded to include more items covering more of the overall content of the training if this were to be repeated as a part of a larger more formal research exercise. 
A pilot study of dual diagnosis training in prisons

Table 1: Mean scores for all participants' baseline and follow-up

\begin{tabular}{|l|c|c|l|l|l|}
\hline Subscale & Baseline (s.d.) & Follow-up (s.d.) & t & df & P value \\
\hline Attitude & $28.90(3.52)$ & $31.29(3.22)$ & 3.839 & 40 & $\mathrm{P}=0.01$ \\
\hline Confidence & $22.23(4.94)$ & $25.44(2.77)$ & -6.03 & 62 & $\mathrm{P}=0.001$ \\
\hline Knowledge & $5.36(1.36)$ & $5.75(1.22)$ & 1.52 & 35 & $\mathrm{NS}$ \\
\hline
\end{tabular}

Table 2: Mean scores for blended and five-day groups' pre and post-training

\begin{tabular}{|l|l|l|l|l|l|l|}
\hline Subscale & $\begin{array}{l}\text { Pre-training } \\
\text { blended (s.d.) }\end{array}$ & $\begin{array}{l}\text { Post-training } \\
\text { blended (s.d.) }\end{array}$ & $\begin{array}{l}\text { Pre-training } \\
\text { five-day (s.d.) }\end{array}$ & $\begin{array}{l}\text { Post-training } \\
\text { five-day (s.d.) }\end{array}$ & $\begin{array}{l}\text { T (difference } \\
\text { post training) }\end{array}$ & $\begin{array}{l}\text { P } \\
\text { value }\end{array}$ \\
\hline Attitude & $29(3.28)$ & $31(3.66)$ & $29.50(3.37)$ & $31.55(3.34)$ & 0.423 & NS \\
\hline Confidence & $22(5.12)$ & $26(3.32)$ & $21.40(5.93)$ & $25.38(3.32)$ & -0.120 & NS \\
\hline Knowledge & $5.56(1.09)$ & $5.95(1.27)$ & $5.20(1.32)$ & $5.60(1.35)$ & -0.905 & NS \\
\hline
\end{tabular}

Table 3: A comparison of mental health and substance use worker mean scores post-training (irrespective of type of training)

\begin{tabular}{|l|l|l|l|l|}
\hline Subscale & $\begin{array}{l}\text { Mental health } \\
\text { workers mean (s.d.) }\end{array}$ & $\begin{array}{l}\text { Substance use } \\
\text { workers mean (s.d.) }\end{array}$ & t & P value \\
\hline Attitude & $30.78(4.20)$ & $31.29(3.25)$ & 0.421 & NS \\
\hline Confidence & $26.16(2.73)$ & $25.00(2.97)$ & -1.474 & NS \\
\hline Knowledge & $5.13(1.40)$ & $6.08(1.17)$ & 2.275 & $\mathrm{P}=0.05$ \\
\hline
\end{tabular}

Table 4: Mean scores for manual and training evaluation

\begin{tabular}{|l|l|l|l|l|}
\hline & $\begin{array}{l}\text { Manual items } \\
\text { mean score (s.d.) }\end{array}$ & Range & $\begin{array}{l}\text { Training/supervision } \\
\text { items mean score (s.d.) }\end{array}$ & Range \\
\hline Blended learning & & & & \\
Highdown & $24(3.0)$ & $21-29$ & $22(1.5)$ & $17-25$ \\
Wandsworth & $24(4.2)$ & $16-28$ & $22(2.6)$ & $17-25$ \\
Belmarsh & $28(2.1)$ & $26-30$ & $22(1.5)$ & $21-24$ \\
\hline Five-day training & & & & $27-30$ \\
Feltham & $27(2.1)$ & $25-30$ & $29(1.1)$ & $24-30$ \\
Wormwood Scrubs & $27(2.2)$ & $24-30$ & $28(2.4)$ & \\
\hline
\end{tabular}


Figure 1: Attitudes scores pretraining and post-training

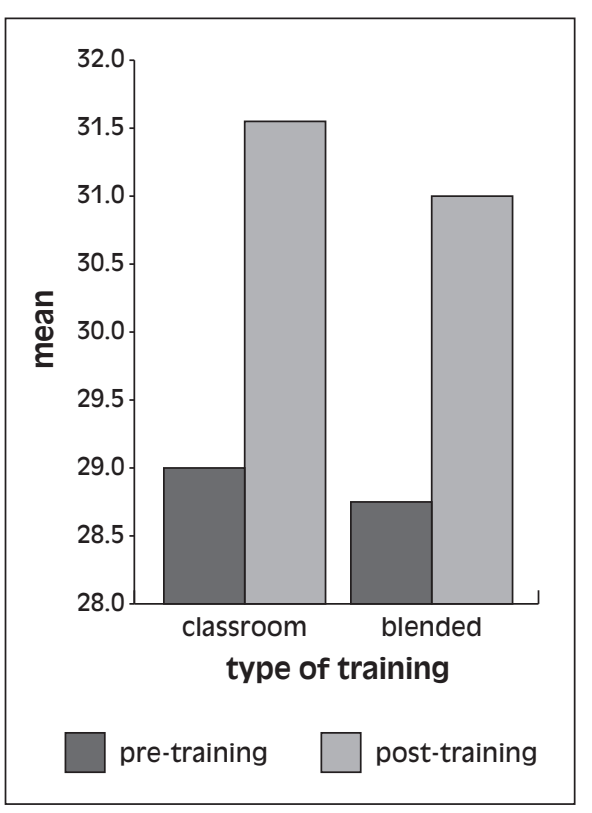

Figure 2: Self-efficacy scores pretraining and post-training

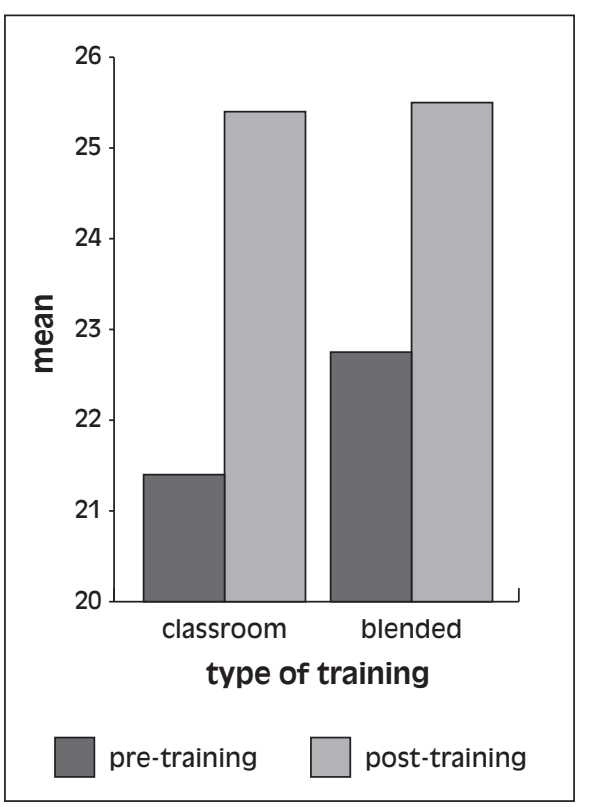

Figure 3: Knowledge scores pretraining and post-training

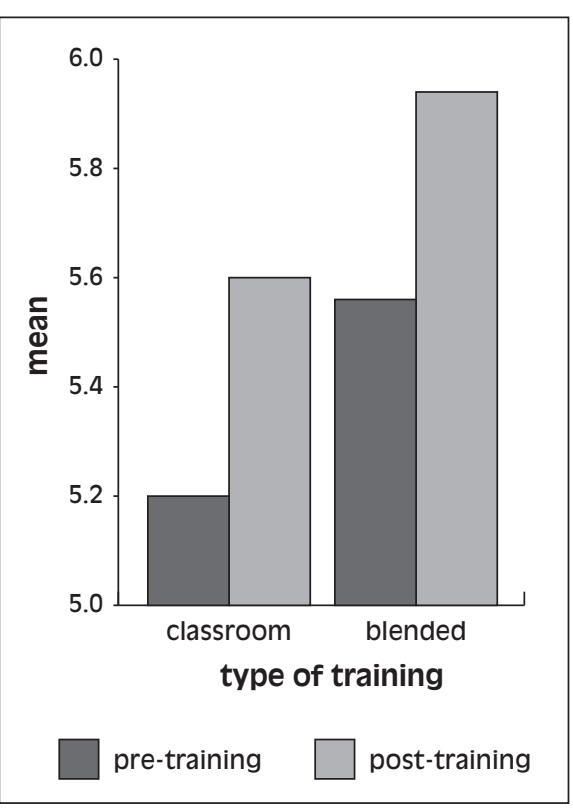

The mean scores for the sections on attitude, confidence in skills, and knowledge were compared between the two training groups (see Figures 1, 2 and 3, above).

Independent $\mathrm{t}$-tests were performed to compare the follow-up means for the two groups and the differences were not statistically significant (see Table 2, opposite).

Those in a mental health role and those in a substance use role were compared on how they responded to the training. Other roles such as psychology, prison officers and general nurses were excluded from the analysis (this excluded six people only). This resulted in 24 staff in the 'substance services' group and 14 in the mental health group. An independent samples t-test compared mean scores for substance use staff and mental health staff at follow-up (see Table 3, opposite).

The only significant difference between substance use and mental health workers was on knowledge. This could be a reflection of the types of items included in the seven items. The items were biased towards substance use issues and therefore it could be hypothesised that the substance use workers were more likely to get these items correct.

In addition to the questionnaire, an evaluation form was devised for the project. This comprised questions relating to the manual, and questions relating to the fiveday training or supervision sessions (five items) in the blended learning. It also included some open-ended questions to obtain qualitative information. The overall score for the manual and the training items was out of a maximum of 30 , and the score for the supervision sessions was out of 25 .

The prison groups were combined to compare all participants who had completed the five-day training with all that had completed the blended (see Table 4, opposite). An independent sample t-test was performed to compare the mean scores for the manual. The mean score for the blended training was 24.85 (s.d. 3.54) and for the five-day training was 27.23 (s.d. 2.07). The five-day training groups evaluated the manual slightly higher than the blended, and this difference was statistically significant ( $\mathrm{t}=2.650, \mathrm{df} 39, \mathrm{p}=0.012)$.

For the qualitative questions they were asked what had they found most useful. Six themes emerged (in order of most frequent response):

- the manual itself

- motivational interviewing techniques

- role-play

- theoretical models and intervention tools

- combining mental health and substance use workers for training

- group discussion. 
Least useful:

- drug awareness/knowledge (mentioned by substance use workers)

- time limits (blended learning only)

- role-play.

Role-play was mentioned in both the 'most useful' and 'least useful' categories but this is not surprising given that some people dislike it and others find it useful.

When asked what was missing from the training that should have been included, the themes were:

- more on mental health, both in the manual and the training

- personality disorders

- attention deficit

- Asperger's syndrome

- exercises and case studies

- information on mental health medications.

It is likely that those people who wanted more on mental health would be the substance use workers, and perhaps this training need may be met by the prison mental health awareness training. When asked what there should be less of, there were few responses, and these consisted of:

- fewer discussions

- drug awareness/knowledge (this was from the substance use workers).

When asked what there should be more of people mentioned:

- role-play and exercises

- discussions

- mental health.

Finally people were asked to give 'any other comments':

- positive comments using terms like 'enjoyable', 'interesting', 'excellently researched', 'useful'

- people were very positive about the manual and felt it would be a useful on going resource

- people who did the blended learning mentioned that time given for the supervision sessions could have been longer or more frequent

- people expressed a wish for further training, and about extending this training to prison officers.
The service user consultants reviewed the training manual and the overwhelming response was very positive. They thought it was clearly set out, simple to read, and succinct. One service user commented that it mapped out the process of working with someone with dual diagnosis very well; it read like a 'journey'. They agreed that the values that they had discussed at the first meeting were clearly represented. They thought that the manual would be accessible to anyone, including service users and carers. They liked the case examples, thought they were credible, and felt there could be more of this.

Some people commented that it was the first time that representatives from the substance use and mental health prison services had sat in a room together for training. They felt this was a real strength of the training, and felt that they got different perspectives on clinical problems as well as sharing expertise and learning about each other's roles.

\section{Discussion and recommendations}

This project has demonstrated that, even given a relatively brief timeframe, it is feasible to set up and deliver dual diagnosis training for prison mental health and substance use services. In addition, the training materials that were developed were evaluated positively by both workers and service user consultants.

The training needs assessment highlighted that prison mental health and substance use staff may lack the capabilities to provide co-ordinated and evidence-based care for people with dual diagnosis. Therefore, it is imperative that a national prison dual diagnosis initiative is implemented to rectify this situation in order for prison services to be able to deliver on government targets (DoH, 2002; DoH, 2005).

Analysis of the outcomes on the knowledge, attitudes and confidence questionnaire (the DDAQ - Dual Diagnosis Attitudes Questionnaire [Hughes et al, in submission]) suggests that overall, the training materials facilitated some positive benefits for the participants. Attitudes and confidence in their skills improved significantly. Knowledge remained unchanged and this has implications for future adaptations of the DDAQ.

The feedback from the two methods of delivery (classroom and blended) suggested that on balance the classroom method was preferable. In addition, the classroom group evaluated the manual more positively. This was perhaps because they had been able to use it 
more thoroughly and in a more structured way. The advantage of the classroom-based training is that groups of workers from different disciplines can work on clinical problems together thus sharing expertise, and learning about each others' roles. This is something that people felt was particularly useful for them.

Further research is required to evaluate the training using more robust methodology. In addition to the evaluation of trainee reactions to the training, it is important that training can demonstrate that it changes practice and in turn improves outcomes for service users. Other important outcomes of training could be at the organisation level, and could be measured by increased effectiveness of multi-agency working.

Dual diagnosis training should be mapped to the prison dual diagnosis strategy that is currently being developed. This will help clarify roles and responsibilities between the agencies and how they can work together. Dual diagnosis training should not represent an end point in itself. It is likely that attendees will identify learning needs as a result of it, and there should be opportunities within the prison and outside to pursue these. This could include the establishment of a forum for the discussion of dual diagnosis issues, and an opportunity to update peoples' knowledge with regular presentations and case presentations.

There is a dual diagnosis training package in development that will be nationally disseminated by Care Services Improvement Programme (CSIP). This will be an advanced training module following on from the 10 Essential Shared Capabilities Framework. This is being developed by the same team who developed the prison pilot project. It is expected that the prison dual diagnosis training would be developed in line with the content and philosophy of this product. This will ensure that prison dual diagnosis training is developed in parallel with other national mental health training initiatives. In addition, both training products will be mapped to the Dual Diagnosis Capability Framework (Hughes, 2006).

\section{Address for correspondence}

Elizabeth Hughes

CCAWI, University of Lincoln

Floor 2, Mill 3

Pleasley Vale Business Park

Outgang Lane

Mansfield

Nottinghamshire

NG19 8RL

Mobile: 07951602199

Tel: 01623819140

Fax: 01623811697

Email: lhughes@lincoln.ac.uk

\section{References}

Brewin E (2004) Sharing the knowledge. Mental Health Today July/August.

Brooker C, Repper J, Beverley C \& Ferriter M (2003) Mental Health Services and Prisoners: a review for the Department of Health [online]. London: Prison Health, Department of Health. Available at: www.dh.gov.uk/assetRoot/04/06/43/78/04064378.PDF [Accessed 31 January 2007].

Brooker C, Ricketts T \& Lemme F (2006) The National Evaluation of the Prison In-reach Collaborative [online]. London: Department of Health. Available at: http://www.nrr.nhs.uk/ViewDocument. asp?ID=M0007126821 [Accessed 31 January 2007].

Department of Health and HM Prison Service (2001) Changing the Outlook - a strategy for developing and modernising mental health services in prison [online]. London: Department of Health. Available at: http://www.phrn.nhs.uk/workstreams/mental health/ChangingTheOutlook.pdf [Accessed 31 January 2007].

Department of Health (2002) Mental Health Practice Implementation Guide. Dual Diagnosis Good Practice Guide [online]. London: Department of Health. Available at: http://personalitydisorder.org.uk/assets/Resources/35.pdf [Accessed 31 January 2007].

Department of Health (2004) The 10 Essential Shared Capabilities - a framework for the whole of the mental health workforce. London: Department of Health.

Department of Health (2005) The National Service Frameworkfive years on. London: Department of Health.

HM Prison Service (1998) Tackling Drugs in Prison. London: HM Prison Service.

HM Prison Service (2000) PSO 3550 Clinical Services For Substance Misusers. London: HM Prison Service.

Home Office (2004) Reducing Re-offending. National Action Plan [online]. London: Home Office. Available at: http://www.probation.homeoffice.gov.uk/files/pdf/NOMS\%20 National\%20Action\%20Plan.pdf [Accessed 31 January 2007]. 
Hughes E, et al (in submission) The Outcomes of Training in Dual Diagnosis Interventions: The COMO Study.

Hughes E (2006) Closing the Gap: a capability framework for working effectively with people with combined mental health and substance use problems (dual diagnosis) [online]. Mansfield: Care Services Improvement Programme and Centre for Clinical and Academic Workforce Innovation. Available at: http://www.lincoln.ac.uk/ccawi/RsrchPublications.htm [Accessed 31 January 2007].

Office for National Statistics (1997) Morbidity in Prisons. Newport: ONS.

Office of National Statistics (1998) Psychiatric Morbidity Amongst Prisoners in England and Wales. Newport: ONS.

Rethink and Turning Point (undated) Dual Diagnosis Toolkit Mental Health and Substance Use [online]. Available via: www.rethink.org/dualdiagnosis/toolkit.html [Accessed 31 January 2007].
Revolving Door (2002) Where Do They Go? Mental Health Housing and Leaving Prison. London: Revolving Door Agency.

Sainsbury Centre For Mental Health (2006) London's Prison Mental Health Services: a review. Policy paper 5. London: Sainsbury Centre for Mental Health.

Shaw J, Appleby L \& Baker D (2003) Safer Prisons. National Study of Prison Suicides 1999-2000 by the National Confidential Enquiry into Suicides and Homicides by People with Mental Illness. London: Stationery Office.

Social Exclusion Unit (2002) Reducing Re-offending by ex-prisoners. Report by the Social Exclusion Unit. London: Office of the Deputy Prime Minister.

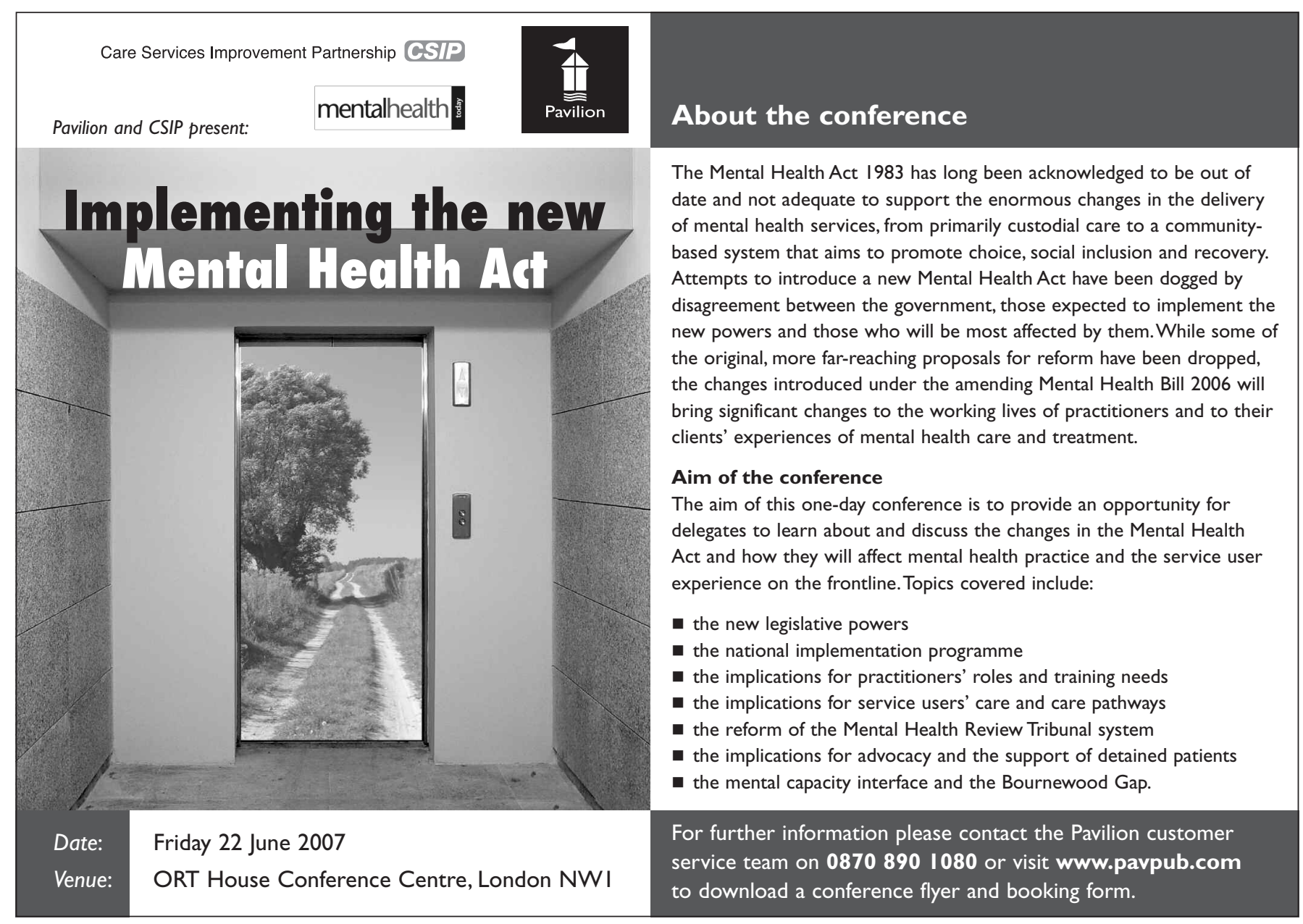

